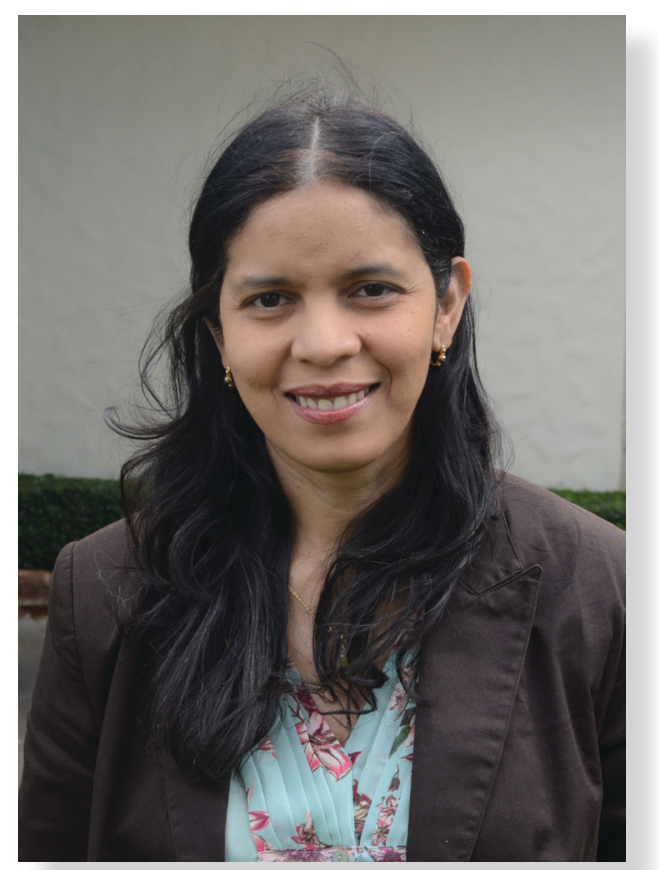

Florilena Paredes

\section{Reseña del libro Competencias cognitivas en Educación Superior}

\author{
Palabras clave \\ competencias; cognitivas; pensamiento crítico; pensamiento \\ creativo; resolución de problemas; Educación Superior
}

L. formación en competencias se ha convertido para la Educación Superior en uno de sus objetivos prioritarios, protagonista de su quehacer y prospectiva.
Llueven los talleres y jornadas para capacitar a los docentes en la compleja tarea de diseñar o rediseñar sus contenidos curriculares con este enfoque dado el hecho de que debemos preparar al estudiante para hacerle frente de manera exitosa a su futuro como profesional y para la vida misma, conociendo que las competencias procuran tres dimensiones o componentes esenciales: un conjunto de habilidades para ejecutar con éxito una determinada tarea; un conjunto general de conocimientos procedentes de disciplinas científicas y una actitud y conducta apropiadas para el desempeño de una función en los diferentes contextos en los que interactúe.

Al hablar de competencias no debemos situar el tema como simplemente un enfoque de educación, como un nuevo modelo al que debemos emigrar dada la realidad compleja de que la Educación Superior impone una permanente redefinición, sino como una preparación para poder actuar de forma eficiente en todos los ámbitos de la vida. Deberíamos reflexionar continuamente y cuestionarnos sobre cuáles son los recursos personales que nos hacen competentes; o con qué frecuencia nos estamos actualizando para mantenernos competentes. Para ser y mantenerse competente ha de ejercitarse el autoanálisis con el fin de conocer las posibilidades de progreso o de fracaso de las que se disponen. Solo las personas que saben observarse y evaluarse críticamente podrán actuar con la disposición suficiente para lograr el efecto que desean. Las competencias proyectan seguridad en un saber conocer, saber hacer y saber actuar y esto permite resolver adecuadamente una tarea o un problema en un contexto definido.

Este importante tema es abordado en Competencias cognitivas en Educación Superior (2010), un excelente libro que ayuda al docente a promover estrategias que perfilan al estudiante como una persona competente: "aquella que posee la creatividad, la disposición y las cualidades necesarias para hacer algo cada vez mejor y justificar lo que hace" (p.15). Su autora, Ma. Luisa Sanz de Acedo Lizarraga, utilizando un lenguaje sencillo ha logrado hermanar la teoría y el proceso complejo de diseñar por competencias a una práctica eficaz y a un método que ella ha denominado "Pensar Activamente en Entornos Académicos" (PAEA). Su principal aporte consiste en ofrecer una serie de estrategias muy útiles para implementar las competencias cognitivas dentro de una práctica educativa eficiente, crítica y significativa que pretende transformar a los estudiantes en personas pensantes que se apropien de manera profunda de los aprendizajes, que sepan transferirlos a distintos contextos y este proceso los capacite para saber tomar decisiones y resolver de la manera más exitosa los problemas que enfrenten.

*Florilena Paredes: Maestría en Lingüística Aplicada por la Universidad de Alcalá de Henares. Acompañamiento pedagógico en el Centro de Desarrollo Académico (CDAC). Coordinadora del Diplomado en Lectura y Escritura a través del CurrículumCSTA que dirige el CEDILE. Coordinadora de la Especialidad en Lingüística Aplicada CSTA. Profesora por asignatura en Postgrado. Para contactar a la autora: florilenaparedes@pucmm.edu.do 
Una de las ventajas que tiene organizar la enseñanza universitaria en función de competencias es la posibilidad de experimentar nuevos métodos didácticos que ayuden a lograr los objetivos que la Universidad pretende. Los teóricos coinciden en que el modelo curricular es un marco de actuación donde se conjuga teoría y práctica, una fuente de preguntas o propuestas y sus direcciones de acción, un equilibrio entre lo real y lo ideal (Castillo Cabrerizo citando a Martínez Santos y Gimeno Sacristán, 2006).
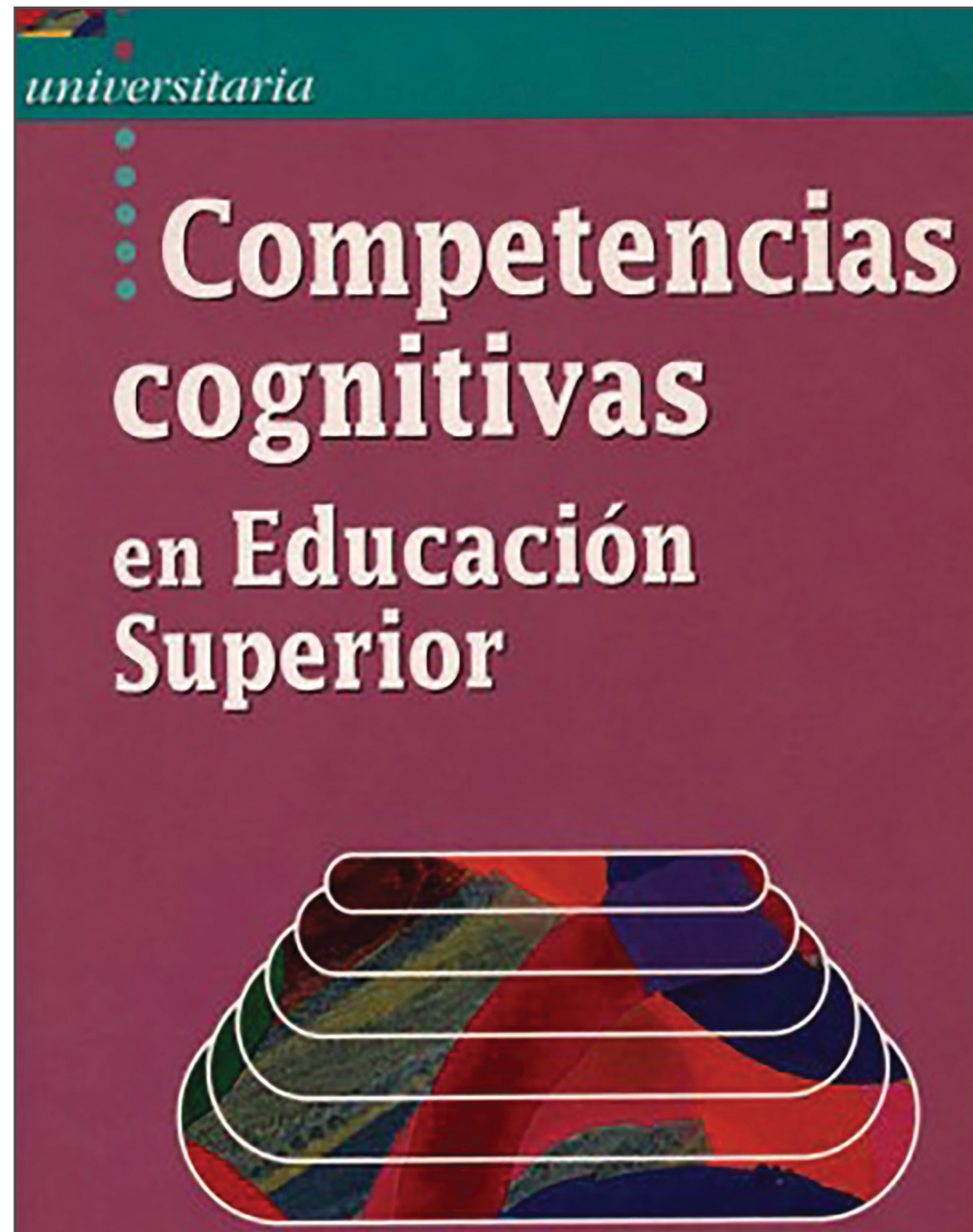

$M^{\mathrm{a}}$ Luisa

SANZ DE ACEDO LIZARRAGA
Dado este planteamiento, la autora de nuestro libro reseñado se pregunta: ¿cuál es la posición actual sobre la enseñanza de las competencias cognitivas? A lo cual concluye diciendo que debe dedicarse un esfuerzo educativo mayor a la enseñanza de las estrategias de pensamiento "para interpretar, ampliar, evaluar y transferir lo aprendido, lo cual no se logrará sin una especial mediación por parte del profesor" (p. 147).

Competencias cognitivas para la Educación Superior es un libro corto, estructurado en siete capítulos de fácil lectura pero con sugerencias muy funcionales apoyadas en el desarrollo del pensamiento crítico. En el capítulo inicial la autora abre su discurso con un planteamiento general, partiendo del constructo competencia, presentando su definición, su relación con términos similares, la clasificación establecida por la Unión Europea y una muestra sencilla y factible de cómo se redacta una competencia, utilizando para toda esta fundamentación y explicación un mínimo de conceptos técnicos. Este panorama inicial es la introducción a su tema principal: las competencias cognitivas, las cuales las clasifica en cinco grupos que forman el perfil completo del pensamiento humano. La autora afirma que estas competencias son las que mejor contribuyen al desarrollo profesional y al éxito en la vida, ya que la mente que piensa bien, interpreta bien, juzga, produce... con un alto grado de imaginación y completa criticidad (p.154).

El capítulo también añade que las competencias pueden ser mejorables en la medida que el sujeto se autoevalúe y descubra su nivel y para esto la autora ofrece un conjunto de prescripciones y buenos 
indicadores para comprobar que una competencia ha sido adquirida, haciendo especial énfasis en el portafolio como un instrumento de evaluación continua y nos da las pautas para su elaboración.

El segundo capítulo está dedicado a las competencias cognitivas del menor nivel de complejidad, aunque no menos importante, ya que cada nivel es un escalón para el siguiente, pues estamos hablando de un desarrollo o estadios del pensamiento. Este primer nivel se le ha denominado pensamiento comprensivo en base al trabajo de Swartz y Parks (1994), y se encarga de procesar e interpretar la información de forma reflexiva y precisa. Su objetivo es la adquisición, representación, transformación, almacenamiento y recuperación de los contenidos a través de habilidades como comparar, clasificar, analizar, sintetizar, secuenciar y averiguar razones y conclusiones.

Sanz de Acedo dice que existe la suposición de que ya se poseen estas habilidades de pensamiento, pero la investigación ha mostrado que esa suposición es falsa, que estas competencias deben ser enseñadas, y aconseja que se les debe prestar la misma atención a las competencias que a los contenidos, por lo cual el plan de estudios debe convertirse en el medio apropiado para enseñar a pensar, a convivir y a actuar de modo tal que los estudiantes tengan la oportunidad de alcanzar un desarrollo óptimo de sus capacidades. (pp. 32 y 42).

Este capítulo dos ofrece una explicación detallada de cada habilidad partiendo de su definición y la manera de conseguirla a través de preguntas que posibilitan su adquisición. La autora añade una representación gráfica con el fin de permitir una superposición de códigos que aumentan la comprensión de la competencia; provee consejos para su evaluación y finaliza con una propuesta o ejemplos de cómo podrían implementarla distintas disciplinas. A manera de cierre, ofrece un resumen. Este patrón se repetirá a lo largo de los siguientes capítulos.

"El modelo educativo por competencias es una opción que busca generar procesos formativos de mayor calidad, sin perder de vista la evolución de la disciplina, de la sociedad y de la profesión" (p. 39). Al hablar de evolución debemos situarnos en el tipo de estudiante que tenemos en frente en nuestro salón y los cambios acelerados en la era del conocimiento en la que vive. Castillo y Cabrerizo dicen con mucha sabiduría que "cada persona es hija de su tiempo", y este momento está definido como una "sociedad moderna, orientada hacia la competitividad, la tecnología y la multiculturalidad y demanda que cada ciudadano intervenga y participe en ella de manera activa, innovadora y responsable" (p.149).
Esto obliga a la Educación Superior a replantearse la manera de enseñar, a entrenar a sus educandos para actuar eficientemente, permitiendo que fomenten el pensamiento crítico para evaluar la información y cuantas ideas y juicios se elaboren. Así que, el capítulo tres se empeña en darnos las características y la manera de usar este tipo de habilidades que incluyen: investigar la fiabilidad de las fuentes de información, descubrir causas, predecir efectos y razonar analógica y deductivamente.

Tal y como establecimos hace poco, estas competencias son más avanzadas que las del capítulo segundo, pues es el paso siguiente a comprender. El pensamiento crítico incluye actividades intelectuales para examinar críticamente con la finalidad de valorar algo para mejorarlo o emitir juicios de aceptación o rechazo siempre basados en argumentos justificados.

Este nivel cognitivo anterior se vincula con el siguiente estadio, la autora declara casi al final de su libro que: "no puede haber pensamiento crítico sin creatividad y no puede haber creatividad sin pensamiento crítico, ambos son inseparables" (p.155). De aquí que, la siguiente competencia cognitiva es el pensamiento creativo. El capítulo cuatro presenta un desarrollo ligeramente diferente a los dos anteriores, debido a que se dedica con más detalles a caracterizar esta capacidad para generar ideas originales e ingeniosas y combinarlas de una manera nueva y productiva (p.69). De hecho, el tema se amplía ofreciendo especificaciones sobre la creatividad como producto, proceso, persona y ambiente y agrega temas de liderazgo como la creatividad grupal y la innovación, considerando este binomio como un proceso emprendedor para producir algo nuevo y práctico.

De manera generosa, la autora nos ofrece características, pasos, fases y luego de este amplio recorrido es que presenta las competencias, su definición y las preguntas esenciales que promueven este tipo de pensamiento. Dichas competencias se han clasificado en: generar ideas, establecer relaciones, producir imágenes, crear metáforas y emprender metas. Dada la riqueza del tema, se nos abre un abanico para que todas las disciplinas encuentren un ejemplo práctico de cómo pueden ser aplicadas dichas competencias a la hora de promover proyectos innovadores y creativos.

El capítulo cinco está dedicado a dos competencias inseparables y que a la vez están muy conectadas con el pensamiento creativo. Se trata de la toma de decisiones y la solución de problemas. Sabemos que cuando practicamos la generación de ideas, nos veremos en la disyuntiva de elegir una decisión u otra. Por otro lado, una solución eficaz a un problema se basa en una decisión eficiente. 
La autora abre este apartado declarando que estas son las competencias más complejas del pensamiento y se les ha llamado competencias superiores. Dada esta importancia, deben ser ejercitadas en todos los planes de estudio de la Educación Superior. Un sujeto que resuelve un problema utiliza competencias comprensivas, evaluativas y creativas, de hecho, la inteligencia se ha definido como la capacidad para solucionar problemas.

Al igual que en el capítulo anterior, Sanz de Acedo hace un estudio más minucioso antes de entrar en las competencias mismas, aunque desde el principio ella aclara que el análisis detallado de este tema sobrepasa sus pretensiones, por lo cual solo presenta una descripción sucinta incluyendo su definición, fases y algunos ejemplos (p. 91).

Lo esencial de este capítulo es la transferencia que posee a cualquier disciplina, a cualquier momento 0 área de la vida. Si necesitamos los pasos para definir un problema y tomar las decisiones más acertadas con menor coste, a predecir consecuencias, a verificar la solución y a evaluar los resultados, este capítulo nos da la guía de cómo aplicar esta competencia. Todo con el objetivo de formar individuos reflexivos que valoran más el proceso que una mera búsqueda de respuesta. La autora cierra diciendo que: "la tarea de enseñar estos procesos supone un gran reto para los profesores, pero no es un reto imposible de alcanzar" (p. 109).

El sexto capítulo presenta los recursos cognitivos, un grupo de competencias que favorecen el desarrollo y el empleo correcto de las que se han presentado en los capítulos anteriores. Estos recursos incluyen la metacognición, la autorregulación y la transferencia. Ellos buscan que el alumno reflexione, interiorice, controle su proceso de aprendizaje, en fin, que se mantenga activo y sea capaz de transferir sus habilidades no sólo en su ámbito académico, sino en su realidad personal, social y laboral.

Las tres dimensiones de los recursos cognitivos motivan el crecimiento intelectual y hacen que el alumno sea una persona cada vez más responsable de sus juicios, comportamientos y resultados, pero son muy difíciles de alcanzar a menos que se enseñen y se practiquen (pp.13 y 111). Los temas de las estrategias metacognitivas y el alumno autorregulado son ampliamente difundidos en el mundo académico, sin embargo, consideramos un valioso aporte de Sanz de Acedo el hecho de dar todas las pautas de cómo se consigue la transferencia de los aprendizajes. La autora declara que: "enseñar a transferir es educar para la vida. Se necesita de este recurso cognitivo para que la Educación Superior alcance las metas que se le han asignado y produzca el impacto que de ella se espera, con el que se sueña" (p. 121).
Como declara la autora en su metatexto inicial al presentar el libro, "el séptimo capítulo pretende ayudar tanto al profesor como al alumno en los procesos de enseñar y de aprender ofreciendo algunas orientaciones psicopedagógicas que conviene tener en cuenta en la nueva programación educativa" (p. 13).

Ma. Luisa Sanz de Acedo es una investigadora muy conocida de la Universidad de Navarra que ha publicado además de este libro, otros cuatro dedicados a pensar activamente en entornos académicos, hasta el punto de ser coautora de un método denominado PAEA, ella considera que el mismo es muy eficaz, completo y eficiente para fomentar las competencias cognitivas en los alumnos y enseñarlos a transferir los aprendizajes a la solución de problemas complejos (p. 126).

Además de mostrarnos las características, pasos, objetivos y justificación del método, este último capítulo agrega otras ideas para aprender una asignatura, entre ellas está la utilidad de las preguntas y nos aporta un fundamento sólido sobre el tipo de preguntas, no solo desde el punto de vista clasificatorio, sino proponiendo un banco de preguntas analíticas y evaluativas que pueden hacerse para indagar y evaluar una asignatura. Como un plus, se añaden dos temas finales por considerarlos que ambos mejoran la calidad de la enseñanza y del aprendizaje: las estrategias y su clasificación y las competencias cognitivas y nuevas tecnologías, las cuales abren nuevos caminos para pensar, adquirir conocimiento y trabajar (p. 142).

Antes de cerrar las conclusiones finales, la autora nos dice que su meta inicial del último capítulo, y podríamos decir que de todo el libro, ha sido mostrar posibles estrategias, y su meta final es la de invitar a los docentes a experimentarlas, a juzgar su viabilidad, comprobar si son prácticas, si dan resultados, nos manda a afinarlas o reelaborarlas en caso de que no nos den el resultado esperado. Estas demandas apuntan al docente competente que hoy requiere la Universidad, que reflexiona sobre su práctica, que investiga sobre su acción.

La editorial Narcea nos ha ofrecido una vez más un libro que todo docente universitario debe leer y beneficiarse de sus aportes. "La calidad de nuestra vida, la calidad de lo que hacemos y producimos, dependen precisamente de la calidad de nuestras competencias" (p. 115).

\section{Referencias}

Castillo Arredondo, S. \& Cabrerizo Diago, J. (2006). Formación del profesorado en Educación Superior. Didáctica y Currículum (Volumen I). Madrid: Mc Graw Hill 